\title{
Peningkatan produktifitas proses produksi sampul raport melalui teknologi tepat guna
}

\author{
Zuliyati $^{1 \star}$, Edwin Djoenaedi ${ }^{2}$, Hutomo Rusdianto ${ }^{3}$ \\ ${ }^{1}$ Universitas Muria Kudus, Indonesia, email: zuliyati@umk.ac.id \\ ${ }^{2}$ Universitas Muria Kudus, Indonesia, email: edwin.djoenaedi@umk.ac.id \\ ${ }^{3}$ Universitas Muria Kudus, Indonesia, email: hutomo_rusdianto@umk.ac.id \\ *Koresponden penulis
}

\section{Info Artikel}

Diajukan: 10 Okt 2020

Diterima: 23 Feb 2021

Diterbitkan: 04 Mar 2021

Keywords:

press machine; bintek;

hydraulic; e-commerce

\section{Kata Kunci:}

mesin press; bintek; hidrolis; e-commerce

\section{Lisensi:}

cc-by-sa

\begin{abstract}
The purpose of this activity is the empowerment of small industries, especially in the cover craftsmen and report cards "GiGa" as service partners. The method used is technology guidance through the application of appropriate technology, assistance in the use of multiuse press machines using hydraulic, e-commerce, financial administration and management assistance. The precise technology of a multipurpose automatic press machine with a hydraulic machine can be used to produce a wide range of quality cover products with an effective and efficient production system. The results of this activity are increasing the ability of independent and resilient partners and increasing the role of the micro industry in development, creating job opportunities, increasing income for cover and report card craftsmen "GiGa" in particular and the country in general, thus realizing a better economy. The output of this activity is an automatic multi-use press machine using hydraulic, effective and efficient production processes, quality cover products.
\end{abstract}

\begin{abstract}
Abstrak
Tujuan dari kegiatan pengabdian ini adalah pemberdayaan industri kecil khususnya pada pengrajin sampul ljazah dan raport "GiGa" sebagai mitra pengabdian. Metode yang digunakan adalah bimbingan teknologi melalui penerapan teknologi tepat guna, pendampingan pemakaian mesin press multi guna menggunakan hidrolis, ecommerce, pendampingan administrasi keuangan dan manajemen. Teknologi tepat guna mesin press serbaguna otomatis dengan mesin hidrolis dapat digunakan untuk memproduksi berbagai macam produk sampul berkualitas dengan sistem produksi yang efektif dan efisien. Hasil kegiatan ini adalah meningkatkan kemampuan mitra yang mandiri dan tangguh serta meningkatkan peran industri mikro dalam pembangunan, menciptakan peluang lapangan kerja, pendapatan yang meningkat pada pengrajin sampul ljazah dan raport "GiGa" pada khususnya serta negara secara umum, sehingga mewujudkan perekonomian yang semakin baik. Luaran kegiatan ini adalah mesin press multi guna otomatis menggunakan hidrolis, proses produksi efektif dan efisien, produk sampul berkualitas.
\end{abstract}

\section{PENDAHULUAN}

Sampul plastik untuk ijazah dan raport saat ini terjadi peningkatan permintaan khususnya sebagai tempat arsip, dokumentasi dan administrasi di 
dunia pendidikan dan lainnya. Sistem Pendidikan saat ini dinilai menggunakan indikator-indikator penilaian secara berkala (Undang-Undang No 20 Tahun 2003), yang dituangkan dalam nilai ijazah dan raport. Mengingat pentingnya ijazah dan rapor tersebut maka kegiatan ini mempunyai tujuan untuk meningkatkan produktivitas UMKM pengrajin sampul raport dan ijazah melalui teknologi tepat guna. Teknologi tepat guna merupakan teknologi yang dapat dikembangkan pada masyarakat tertentu, agar dapat membawa manfaat bagi masyarakat sehingga membawa kehidupan yang efektif dan efisien (Gunawan, 2014; Rahmiyati et al., 2015; Antara, 2015). Proses produksi yang membutuhkan waktu lebih lama menjadi lebih singkat, lebih praktis dan kualitas lebih baik.

Tujuan dari kegiatan pengabdian ini adalah pemberdayaan industri kecil khususnya pada pengrajin sampul ljazah dan raport "GiGa" sebagai mitra pengabdian, melalui penerapan teknologi tepat guna. Mitra diharapkan dapat memproduksi berbagai macam produk berkualitas dengan menggunakan mesin press serba guna serta sistem produksi yang efektif dan efisien (Taufiqurrahman et al., 2018). Selain itu menjadikan mitra sebagai UMKM yang tangguh dan berperan aktif dalam pembangunan daerah sehingga omset penjualan pengrajin sampul ijazah dan raport "GiGa" meningkat. Mitra kegiatan mempunyai omset setiap tahunnya $R p$ 250.000.000, sehingga tergolong sebagai usaha mikro dilihat dari jumlah penjualannya tidak lebih dari $\mathrm{Rp}$ 300.000.000 per tahun (Undang-Undang Republik Indonesia No.20 Tahun 2008).

Permasalahan yang dihadapi oleh mitra adalah keterbatasan sumber daya manusia akan penguasaan teknologi, sehingga mereka belum sepenuhnya mampu mengoperasikan mesin press untuk memproduksi sampul ijazah dan raport. Bimbingan teknologi akan meningkatkan sumber daya manusia sebagai modal intelektual, agar memiliki keunggulan kompetitif (Nahdhah, 2017; Zuliyati \& Delima, 2019).

\section{METODE PELAKSANAAN}

Metode yang digunakan dalam memecahkan permasalahan yang dihadapi, mitra bersama tim pengabdian dengan mengadakan forum diskusi memberikan solusi untuk mengatasi permasalahan tersebut melalui implementasi dari penerapan dan pengembangan teknologi tepat guna (Jumino, 2019). Pemilihan teknologi tepat guna memakai bermacam analisis kelayakan menyesuaikan dengan kebutuhan (Nilasari et al., 2019). Metode yang digunakan dalam kegiatan pengabdian ini adalah sebagai berikut:

1. Meningkatkan Sumber Daya Manusia melalui:

a. Peningkatan pengetahuan pengrajin sampul ijazah dan raport tentang pentingnya teknologi tepat guna dengan cara bimbingan teknologi tepat guna. Gambar 1 menunjukkan bimbingan teknologi pengoperasian mesin pembuatan sampul menggunakan hidrolis.

b. Pendampingan usaha dalam penggunaan mesin press multi guna menggunakan hidrolis untuk meciptakan inovasi produk sampul ijazah, rapor, Plastik pembungkus, kantong STNK, dompet SIM, 
sampul BPKP, dsb sehingga mitra mempunyai keunggulan kompetitif, mampu bersaing dalam pemasaran.

c. Pendampingan manajemen administrasi pengelolaan usaha serta administrasi keuangan dalam penyusunan laporan keuangan sesuai standar keungan, pendampingan pengisian SPT sehingga pengelolaan usaha akan terencana dengan baik, efektif dan efisien.

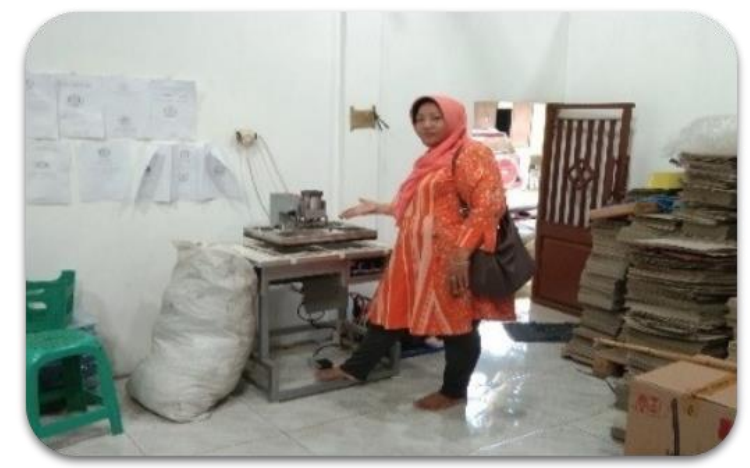

Gambar 1. Pendampingan usaha membuatan produk sampul ijazah

2. Peningkatan peralatan usaha tepat guna dengan memperkenalkan alat yang berbasis mesin, sehingga tidak sepenuhnya mengandalkan tenaga manusia. Peningkatan sarana yang digunakan dari mesin press manual menjadi mesin press hidrolis diharapkan akan meningkatkan produktifitas dalam menghasilkan produk. Gambar 2 dibawah ini merupakan mesin press manual yang akan di tingkatkan menjadi mesin multi guna menggunakan mesin hidrolis

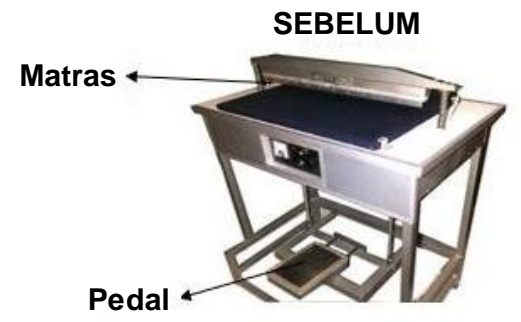

cara kerja menggunakan sistem manual dengan menginjak pedal dengan waktu 30 detik, baru bisa menyambungkan plastik pada matras sehingga pekerja harus memperkirakan waktu 30 detik untuk melepas pedal

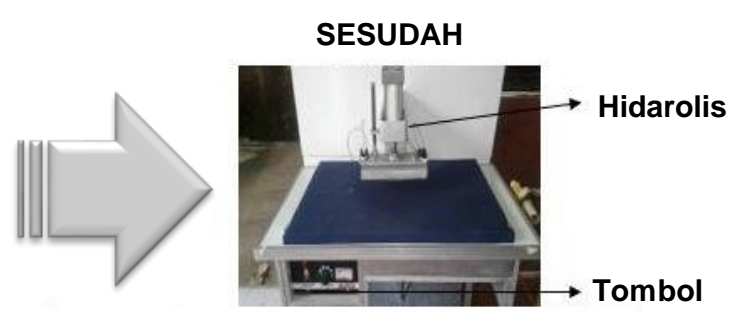

cara kerja menggunakan sistem hidrolis dengan menekan tombol matras akan otomastis mengepres palstik dan dalam waktu 30 detik akan terangkat

Gambar 2. Peningkatan mesin press manual menjadi hidrolis

3. Pemasaran melalui e-commerce

Melalui pengembangan e-commerce yang sudah ada, diharapkan pemasaran menjadi lebih luas, sehingga permintaan produk menjadi semakin banyak. Perluasan jaringan Kerjasama dengan instansi terkait juga sangat diperlukan untuk memperluas pemasaran produk raport dan 
ijazah (Zuliyati, 2015; Setiyorini et al., 2018). Gambar 3 dibawah ini adalah pemasaran online produk-produk yang dihasilkan oleh mitra.

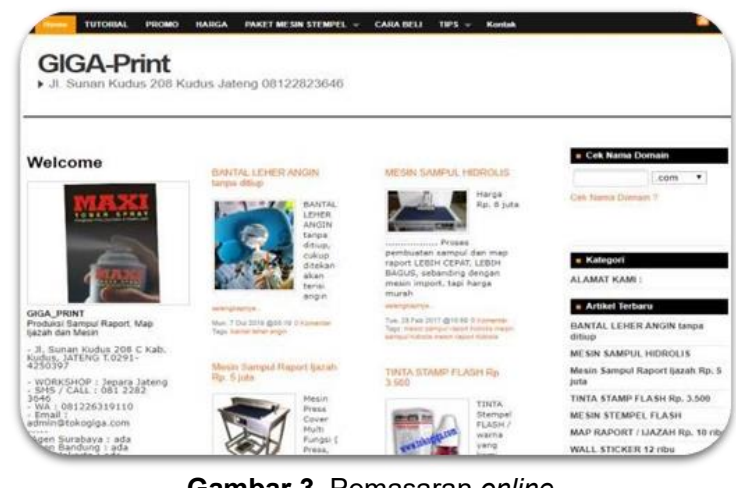

Gambar 3. Pemasaran online

\section{HASIL DAN PEMBAHASAN}

Hasil kegiatan pengabdian ini adalah adanya peningkatan sumber daya manusia, terlihat dari pengrajin yang sebelum adanya kegiatan ini tidak mempunyai keberanian untuk menggunakan teknologi berbasis mesin menjadi berani beralih menggunakan peralatan press hidrolis. Pelatihan dan pendampingan usaha dalam penggunaan mesin press multi guna menggunakan hidrolis dapat meciptakan inovasi produk sampul ijazah, rapor, plastik pembungkus, kantong STNK, dompet SIM, Sampul BPKP, dsb. Pelatihan dan pendampingan manajemen administrasi pengelolaan usaha serta administrasi keuangan dan penyusunan laporan keuangan sesuai dengan Standar Akuntansi EMKM, sehingga pengelolaan usaha akan terencana dengan baik, efektif dan efisien.

Sarana dan prasarana menjadi meningkat. Pelatihan praktek menggunakan alat bebasis mesin seperti, alat pemotong plastik roll, alat tembak lem dan paku menjadikan pekerjaan lebih cepat, praktis dan efektif. Penyelesaian pekerjaan tidak sepenuhnya mengandalkan tenaga manusia. Peningkatan sarana yang digunakan dari mesin press manual menjadi mesin press hidrolis diharapkan akan meningkatkan produktifitas dalam menghasilkan produk.

Pemasaran yang luas melalui e-commerce. Pemasaran yang sebelumnya secara konvensional hanya berdasarkan pesanan pelanggan lama, menjadi pemasaran pada marketplace yang lebih luas. Mitra sangat antusias dalam praktek pemasaran online melalui shopee, facebook maupun Instagram.

Melalui pengembangan e-commerce yang sudah ada, menjadikan pemasaran menjadi lebih luas, sehingga permintaan produk menjadi semakin banyak. Produk sampul ijazah dan raport menjadi lebih berkualitas karena kerapian, tingkat kerekatan sambungan lebih bagus. Hasil produk dapat dilihat di gambar 4. Mesin ini selain dapat digunakan untuk menghasilkan sampul ijazah dan raport dengan hasil press bagus dan langsung memotong, lebih 
rapi yang juga sisa bahan bisa dimanfaatkan menjadi dompet kecil,sampul pasport, bungkus sarung, mukena, sajadah dll.

Beberapa cara dalam memproduksi barang yang kreatif dan inovasi, Kotler 2015: (1) atribut produk baru yang dikembangkan, (2) beragam tingkat mutu yang ditingkatkan, (3) model dan ukuran produk yang dikembangkan. Gambar dibawah ini merupakan peningkatan mutu dari produk yang sebelumnya dengan menggunakan mesin press hidrolis.

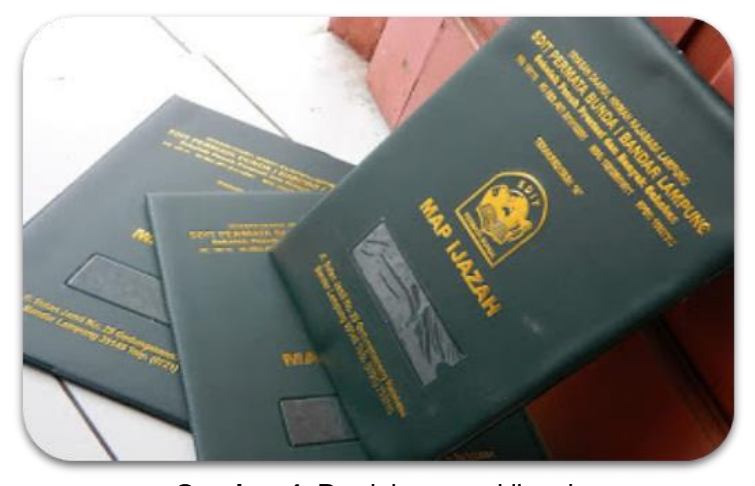

Gambar 4. Produk sampul ijazah

\section{KESIMPULAN}

Kegiatan pengabdian ini sangat bermanfaat bagi mitra ditunjukkan dengan adanya peningkatan produktifitas karena adanya peningkatan sumber daya manusia. Keberhasilan kegitan ini ditunjukkan dengan adanya kenaikan pendapatan sebesar $10 \%$ dari omset tahun sebelumnnya. Teknologi tepat guna sangat membantu mitra dalam melakukan usahanya, selain itu pengetahuan mitra akan administrasi keuangan, perpajakan meningkat dilihat dari kemempuan mitra dalam menyusun laporan keuangan dan mampu menyusun dan melaporkan SPT. Pemasaran melalui online atau internet menjadikan produk mitra terkenal dan diketahui kalayak masyarakat umum.

Namun demikian pada saat ini produk map mengalami ancaman dikarenakan map yang biasanya digunakan untuk kurikulum 13, ternyata saat ini ada sebagian sekolah yang tidak melanjutkan kurikulum 13. Disarankan pemerintah konsisiten dalam mengeluarkan kebijakan. Mitra diharapkan lebih aktif dalam proses pelaksanaan kegiatan, dan dharapkan bisa menjadi percontohan bagi mitra yang lain.

\section{UCAPAN TERIMA KASIH}

Ucapan terima kasih kami sampaikan kepada Lembaga Penelitian dan Pengabdian Universitas Muria Kudus yang telah mendanai dalam kegiatan pengabdian kepada masyarakat melalui skim pengabdian teknologi tepat guna. 


\section{DAFTAR RUJUKAN}

Antara, G. E. D. (2015). Peningkatan Inovasi Teknologi Tepat Guna dan Program Berbasis Pemberdayaan Masyarakat untuk Memajukan Industri Kreativ di Bali. Jurnal PASTI (Penelitian Dan Aplikasi Sistem Dan Teknik Industri), 9(3), 257-268. https://publikasi.mercubuana.ac.id/index.php/pasti/article/view/489

Gunawan, B. (2014). Proses Pemberdayaan Usaha Kecil Menengah Melalui Penerapan Teknologi Tepat Guna (Studi Pada Dua Mitra Binaan Pos Pelayanan Teknologi Tepat Guna Karya Mandiri Kecamatan Tegowanu Kabupaten Grobogan) [Universitas Negeri Semarang]. https://lib.unnes.ac.id/23556/1/1201410035.pdf

Jumino. (2019). Partisipasi Masyarakat melalui Kelompk Tani dalam Program Pengembangan dan Pemanfaatan teknologi Tepat Guna Bidang Pertanian.

Nahdhah, N. (2017). Strategi Pengembangan Sumber Daya Manusia Dalam Meningkatkan Keunggulan Kompetitif (Studi Kasus di Pondok Pesantren Hidayatullah Balikpapan). Universitas Islam Negeri Maulana Malik Ibrahim Malang.

Nilasari, A. P., Hutajulu, D. M., Retnosari, \& Puji Astutik, E. (2019). Strategi Pemberdayaan dan Kontribusi UMKM Menghadapi Ekonomi Digital. Prosiding SEMINAR NASIONAL DAN CALL FOR PAPERS, 576-594.

Rahmiyati, N., Andayani, S., \& Panjaitan, H. (2015). Model pemberdayaan masyarakat melalui penerapan teknologi tepat guna di Kota Mojokerto. Jurnal Ilmu Ekonomi \& Manajemen, 2(2), 48-62. https://doi.org/10.30996/jmm.v2i02.506

Setiyorini, E. S., Noorachmat, B. P., \& Syamsun, M. (2018). Strategi Pemasaran Produk Olahan Hasil Perikanan pada UMKM Cindy Group. MANAJEMEN IKM: Jurnal Manajemen Pengembangan Industri Kecil Menengah, 13(1), 19-28. https://doi.org/10.29244/mikm.13.1.19-28

Taufiqurrahman, M., Purwoko, B., \& Meilasari, F. (2018). Pemberdayaan Masyarakat Kelompok Petani Desa Jungkat Kecamatan Siantan Kabupaten Pontianak dan Desa Rasau Jaya Umum Kecamatan Rasau Jaya Kabupaten Kubu Raya. Al-Khidmah, 1(1), 44-52. https://doi.org/10.29406/al-khidmah.v1i1.1051

Undang-Undang No 20 Tahun 2003. (n.d.). Tentang Sistem Pendidikan Nasional.

Undang-Undang Republik Indonesia No.20 Tahun 2008. (n.d.). Tentang Koperasi dan UMKM.

Zuliyati, Z. (2015). Pengembangan Industri Kreatif Pigura Kaligrafi Menuju Pasar Global. Ajie, 4(3), 202-207. https://doi.org/10.20885/ajie.vol4.iss3.art7

Zuliyati, Z., \& Delima, Z. (2019). Analysis Of Intellectual Capital Management Success Through The Improvement Of Micro, Small, And Medium Enterprise (MSME) Performance On Food And Beverages In Kudus Regency. https://doi.org/10.4108/eai.24-10-2018.2280528 